\title{
P-0305- Metabolic alterations in obese adults with obstructive sleep apnea
}

\author{
Jamoussi H; Ben Othman R; Berriche O; Mahjoub F; Gaigi I
}

Department $A$ of the national institute of Tunis, Tunisia

\section{Introduction:}

Obstructive sleep apnea (OSA), a disorder of breathing during sleep, is very frequently associated with obesity. the OSA has also been implicated in many inflammatory and hormonal disturbances involving the mechanism of leptin and adiponectin. This work proposes to compare the anthropometric parameters, metabolic, inflammatory and hormonal in an obese group divided into two groups apneic and non apneic according to results of a ventilatory polygraphy.

\section{Methods:}

Our population consists of 105 obese who looked between October 2012 and January 2013.45 of them have been identified at risk for OSA by Berlin questionnaire and underwent a polygraph ventilator. Patients underwent anthropometric measurements and laboratory tests including dosage of adiponectin, leptin and crp hs.

\section{Results:}

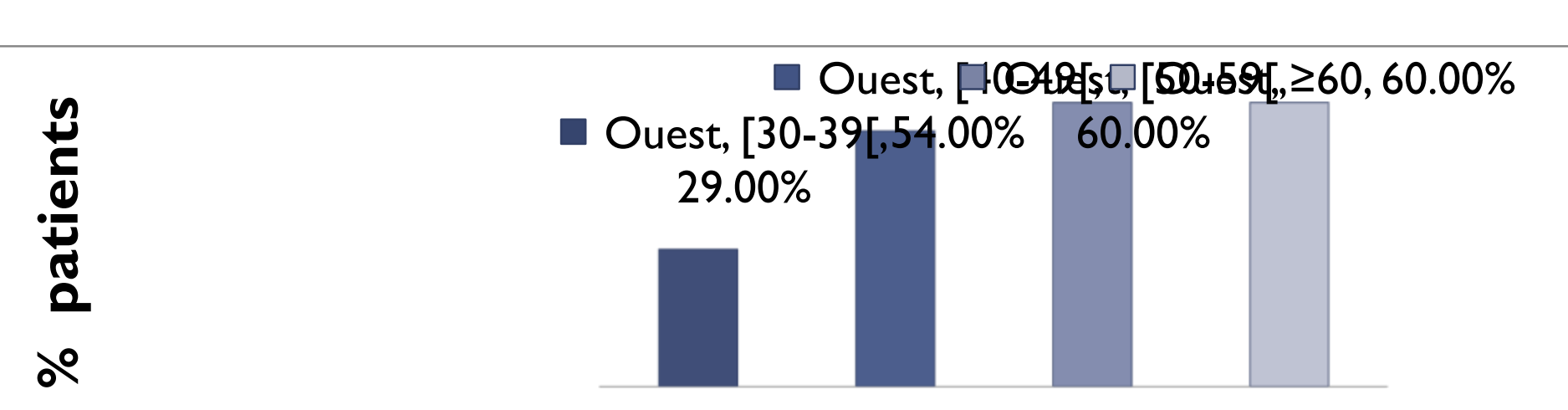

Fig I: age of the patients

$64 \%$

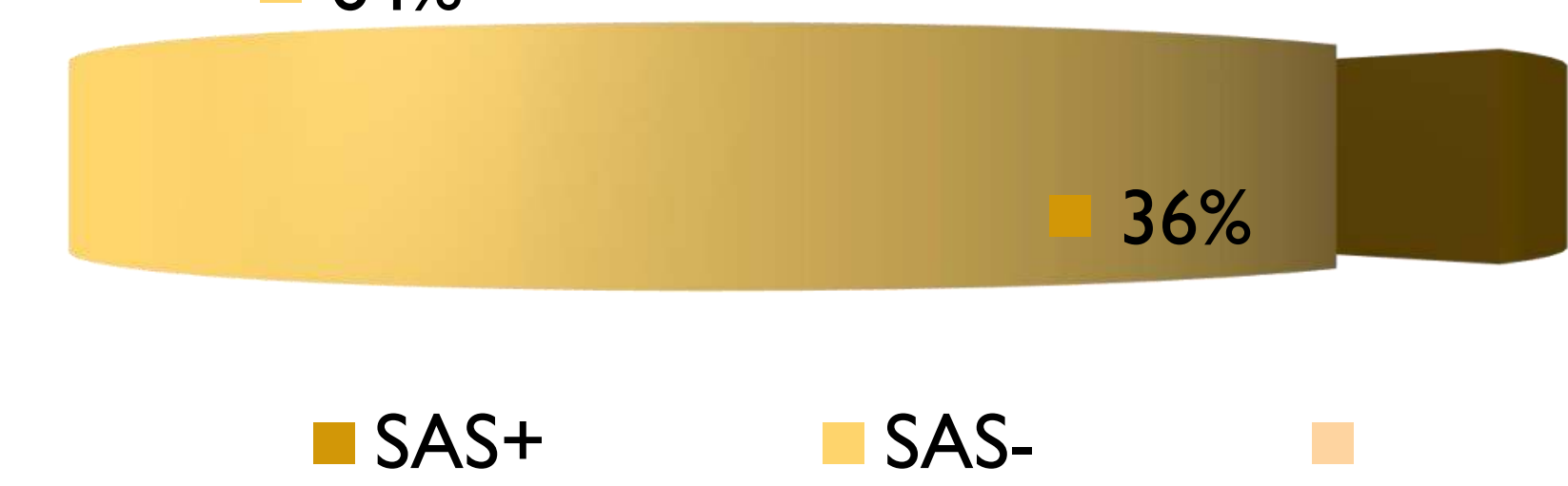

Fig 2: SAS in the population

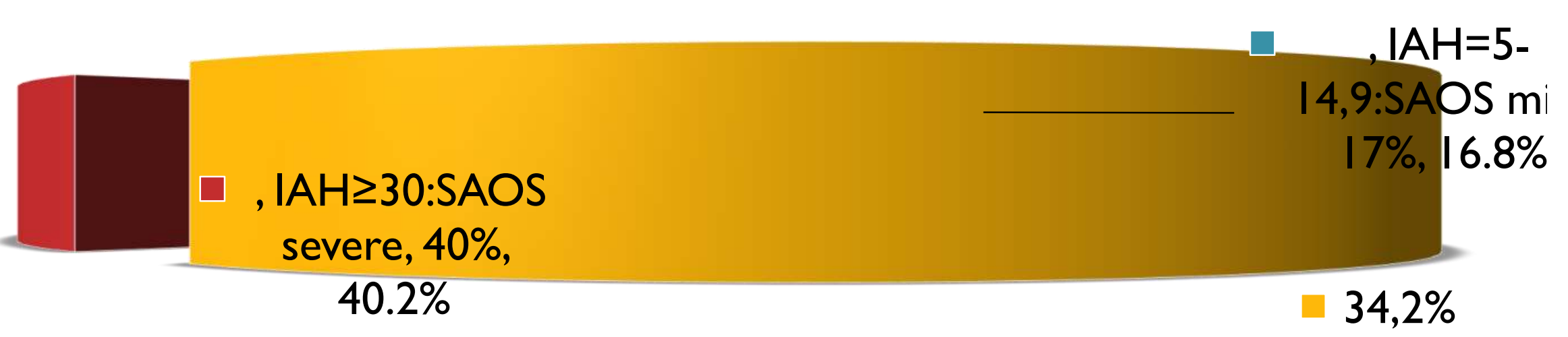

- IAH=5-14,9:SAOS mild - IAH $\geq 30: S A O S$ severe

Fig 2: Severity of SAS in the population

Tabl I: anhropometric differences between the two groups

\begin{tabular}{|c|c|c|c|}
\hline & $\begin{array}{c}\text { Non-apneic } \\
(\mathrm{n}=67)\end{array}$ & $\begin{array}{c}\text { Apneic } \\
(\mathrm{n}=38)\end{array}$ & P value \\
\hline Age $($ years) & $42 \pm 12$ & $48.5 \pm 9$ & NS \\
\hline BMI $\left(\mathrm{Kg} / \mathrm{m}^{2}\right)$ & $38.4 \pm 5.7$ & $43.8 \pm 7.5$ & 0.001 \\
\hline Neck circumference $(\mathrm{cm})$ & $37 \pm 2.4$ & $40.3 \pm 3$ & 0.001 \\
\hline Waist circumference $(\mathrm{cm})$ & $113.6 \pm 16.2$ & $125.5 \pm 15.3$ & 0.002 \\
\hline
\end{tabular}

\section{Conclusions:}

Tabl2: lipidic and glucidic profile of the popuation

\begin{tabular}{|c|c|c|c|c|}
\hline $\begin{array}{l}\text { variables } \\
\end{array}$ & \begin{tabular}{|l|} 
Mild OSA \\
$(n=7)$
\end{tabular} & $\begin{array}{l}\text { Moderate OSA } \\
(\mathrm{n}=16)\end{array}$ & \begin{tabular}{|l} 
Severe OSA \\
$(n=15)$
\end{tabular} & $p$-value \\
\hline $\begin{array}{l}\text { Total Cholesterol } \\
(\mathrm{mmol} / \mathrm{I})\end{array}$ & $4.54 \pm 0.86$ & $4.89 \pm 1.09$ & $4.58 \pm 0.95$ & NS \\
\hline Triglycerides (mmol//) & $1.15 \pm 0.9$ & $1.71 \pm 1.01$ & $1.29 \pm 0.46$ & NS \\
\hline HDL-C (mmol/l) & $1.21 \pm 0.59$ & $0.88 \pm 0.28$ & $0.89 \pm 0.30$ & NS \\
\hline LDL-C (g/l) & $1.08 \pm 0.26$ & $1.25 \pm 0.32$ & $1.2 \pm 0.37$ & NS \\
\hline $\begin{array}{l}\text { Fasting blood glucose } \\
\text { (mmol/l) }\end{array}$ & $5.80 \pm 1.2$ & $7.14 \pm 4.21$ & $7.16 \pm 3.11$ & NS \\
\hline Fasting insulin $(\mu \mathrm{Ul} / \mathrm{ml})$ & $12.85 \pm 3.55$ & 15.5117 .94 & \begin{tabular}{|l|l|}
14.9115 .64 \\
\end{tabular} & NS \\
\hline HOMA-IR & $3.42 \pm 1.63$ & $4.89 \pm 3.48$ & $5.17 \pm 3.51$ & NS \\
\hline
\end{tabular}
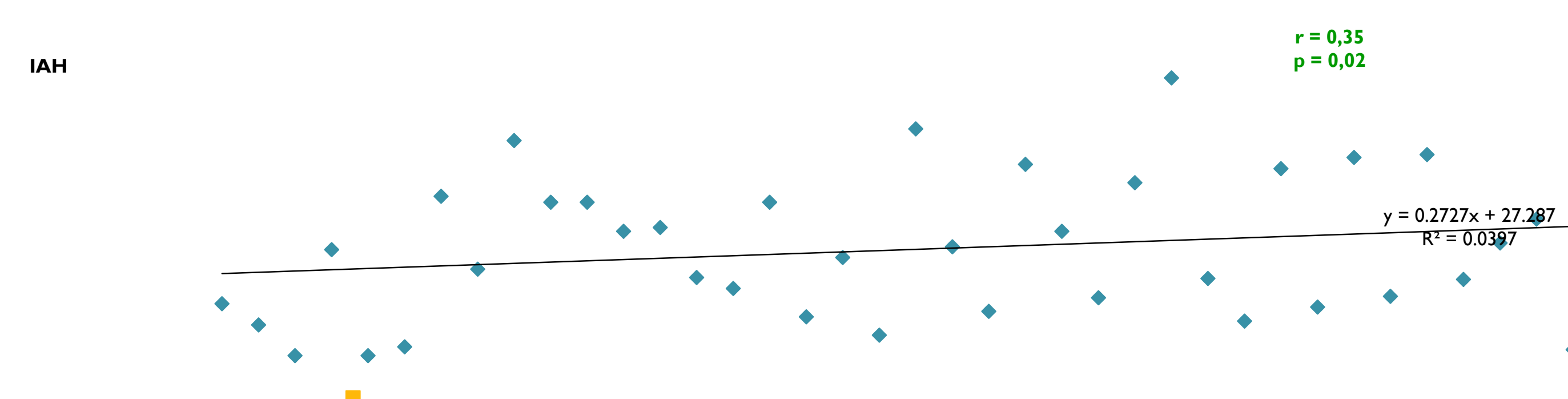

Fig 3: Relation between AHI and CRP hs

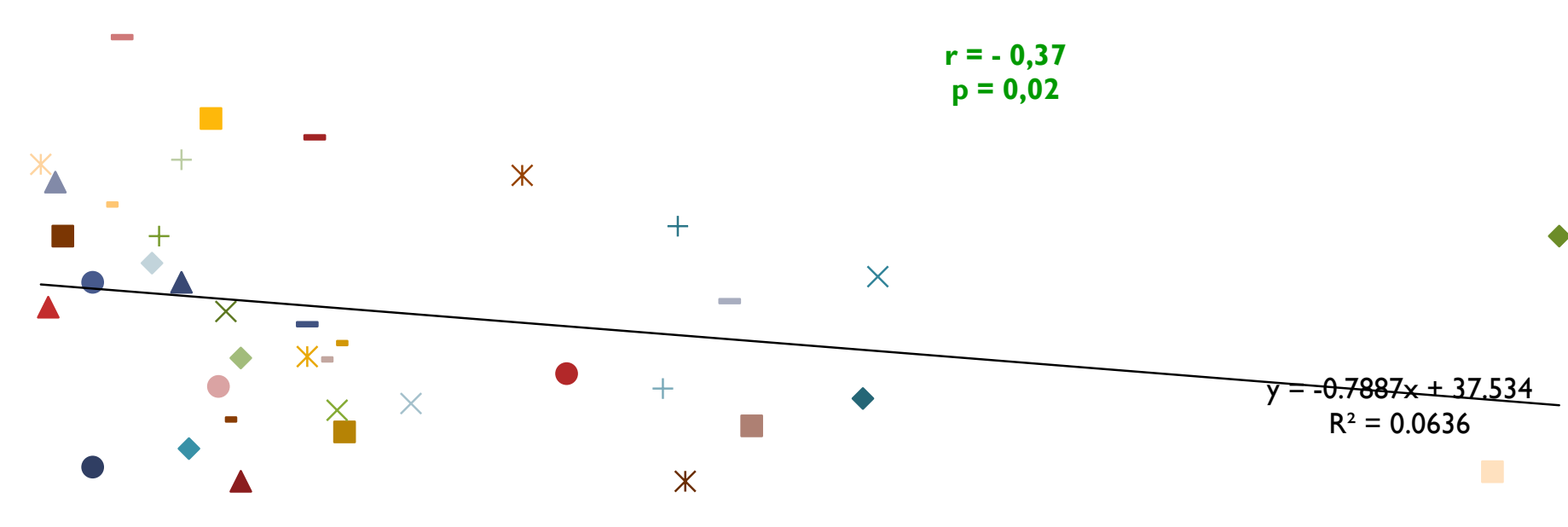

Fig 4 : relation between $\mathrm{AHI}$ and adiponectin

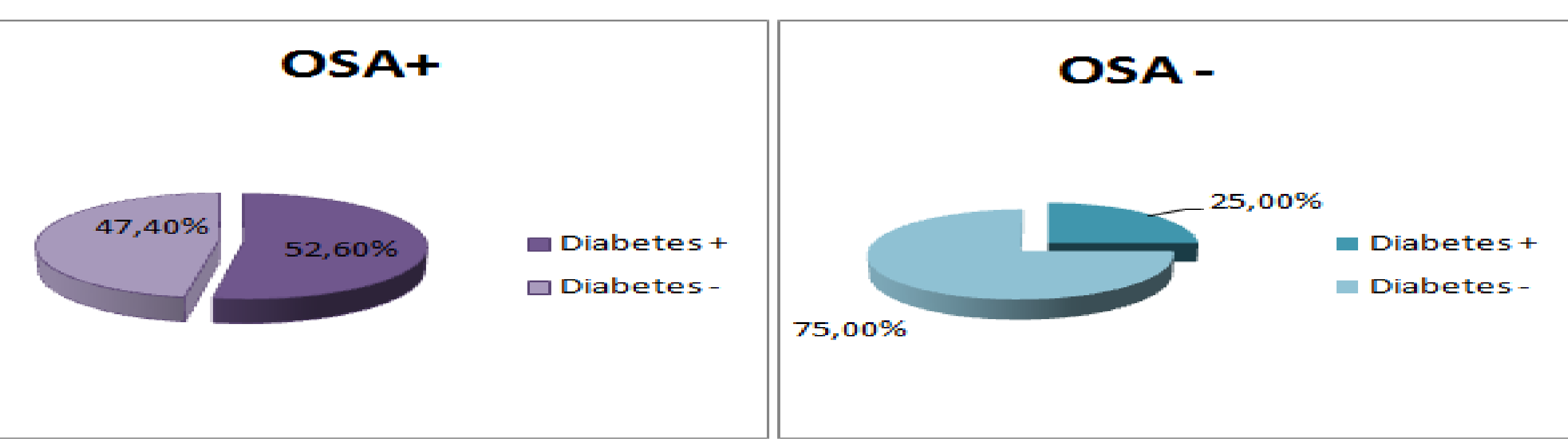

Fig: prevalence of type 2 DM in the obeses with and without osA

The frequency of type 2 diabetes was doubled in patients with OSA $(p=0.004)$

- The prevalence of OSA in our obese studied population was 36,2\%. The prevalence of OSA in our obese studied population was 36,2\%. Many studies have shown an increase of $10 \%$ of body weight or $6 \mathrm{~kg} /$ $\mathrm{m}^{2}$ in BMI multiply by six the risk of the following four years with moderate to severe OSA [I]. -OSA severity was associated with blood glucose levels, CRP hs and adiponectin. -Studies on the relationship between OSA and CRP have yielded conflicting results due to the confounding effects of obesity. Some investigations have found an independent correlation of OSA and CRP levels [2] , while others have failed to show this relationship [3]

Peppard PE, Longitudinal study of moderate weight change and sleep-disordered breathing. JAMA. 20 déc 2000;284(23):3015-21.

. Ryan S.Cardiovascular risk markers in obstructive sleep apnoea syndrome and correlation with obesity. Thorax. juin 2007;62(6):509-14. Pamidi S, Tasali E. Obstructive sleep apnea and type 2 diabetes: is there a link? Front Neurol. 2012;3:126. 